\title{
Evidence for longevity differences between left handed and right handed men: an archival study of cricketers
}

\author{
John P Aggleton, Robert W Kentridge, Nicholas J Neave
}

\begin{abstract}
Study objective-The aim was to examine the relationship between handedness and longevity.

Design-This was an archival (retrospective) survey of a cohort of adult men who had played 'first-class cricket'.

Setting-The United Kingdom

Participants-The subjects consisted of all of the deceased players included in an encyclopaedia of 'first-class cricket' whose bowling hand had been recorded $(n=3165)$. The study also considered a further 2314 players, born before 1951 but still alive at the time the book was published (1984).

Measurements and main results-Using the bowling hand as an indicator of handedness it was possible to compare the lifespans of 2580 right handed men and 585 left handed men. The average life spans of the two groups differed by 25 months (right $=65.62$, left=63.52), a highly significant difference $(p=0 \cdot 006)$. An examination of cause of death (where noted) strongly indicated that the left handed men were more likely to die prematurely in accidents or in warfare. As a consequence, when these unnatural deaths were removed from the sample the longevity difference between the right handers and left handers was considerably reduced. There was no evidence that these results related to any longitudinal change in the proportion of right handers to left handers across the time course of the sample.

Conclusion-The study found clear evidence that left handedness was associated with a decrease in longevity among a cohort of adult, athletic men. A major factor responsible for this result seemed to be a differential likelihood of accidental death or death during warfare.
\end{abstract}

f Epidemiol Community Health 1993; 47: 206-209

Cross sectional surveys of handedness among the adult population have repeatedly shown a decline in left handedness with increasing age. ${ }^{1-4}$ This has been attributed to a number of possible factors These include changes in the teaching of left handers as well as the suggestion that left handers become increasingly adept at living in a 'right handed world', so learning with advancing age to do more things with the right hand. ${ }^{14}$ There is, however, a further possibility - that left handedness is associated with a shorter life expectancy.

The claim that left handedness may be linked with a change in longevity has aroused much controversy. Support for the notion that left handers may die younger has come from comparisons of the lifespans of baseball players, ${ }^{45}$ from evidence that left handed people suffer more serious accidents, ${ }^{46}$ and from cross sectional surveys of age at the time of death. ${ }^{7}$ These findings have, however, been disputed on both statistical grounds ${ }^{89}$ and on the need to have data on the entire population under consideration. This latter criticism is important as there may be a systematic bias among those subjects not included in the survey.

Different evidence to suggest that handedness may be associated with a change in life expectancy has come from the proposal that left handedness is linked with an increased incidence of certain diseases, including immune disorders. ${ }^{10-12} \mathrm{~A}$ number of recent studies have, however, failed to replicate some of these finding ${ }^{13-15}$ and so the status of this association remains uncertain.

The present study re-examined the possible link between handedness and longevity by comparing the lifespans of cricketers. This population was selected because it has been very carefully and very comprehensively documented, and because a major feature of play (bowling) provides an accurate indicator of handedness. ${ }^{1617}$ As a consequence, it is possible to determine the life spans and likely handedness of an entire cohort of subjects. It should be added that batting hand (the lower hand on the bat) is a poorer indicator of handedness as it requires two hands to bat and some genuine right handers are known to play 'left handed' and vice versa. ${ }^{16}$

\section{Methods}

All data were taken from the Who's Who of Cricketers. ${ }^{18}$ This book describes all 'first-class' cricketers in the British Isles from 1864 to 1983 , plus some of the most prominent earlier players. As a consequence most of the subjects were born in the British Isles. The book contains the dates of birth and death for each player. For those players who were born or died in England and Wales these dates were confirmed against the records of the General Register Office, London. The book also lists, where known, the hand used for batting and bowling. Bowling hand could also be deduced in those players described as bowling 'off-break', 'leg-break', or 'leg-break googly' as these terms only refer to right handers (as confirmed by an author of the encyclopaedia). The book ${ }^{18}$ also records the cause of death if it is regarded as unusual or, when known, in the case of a player who died young.

Birth and death dates were compiled for every deceased player whose bowling hand could be 
determined $(n=3165)$. The batting hand was also noted for these same subjects. In addition, the year of birth was recorded for those players $(n=2314)$ born before 1951 but still alive at the time of book publication (1984). Once again, this only applied to those players for whom the bowling hand could be determined. Four players who could bowl with either hand were excluded from the study. The total of 5479 subjects considered in the resultant sample constituted approximately $55 \%$ of all of the cricketers listed in the Who's Who of Cricketers $^{18}$ as being born before 1951 .

DATA ANALYSIS AND STATISTICAL METHODS The first analyses examined whether the ratio of left handed to right handed players was stable across the period of the sample. This was achieved by taking groups of 10 left handers, starting from the earliest birth year (1734), and calculating the number of right handers born in the same period (fig 1). This analysis involved all of the subjets born before 1951 ( $n=5479)$.

The life spans of the deceased left and right handed players were compared with a $t$ test (two tailed). Although the age distributions for both sets of players were negatively skewed (fig 2), the similarity in their shapes permits the unbiased use of parametric statistics. ${ }^{19}$ The $\chi^{2}$ was used for subsequent tests of frequency, and in all cases there was one degree of freedom.

\section{Results}

The study consisted of 3165 deceased players. According to their bowling hand these players could be divided into 585 left and 2580 right handed cricketers, a ratio of $1: 4.41$. When the entire population of cricketers born before 1951 $(n=5479)$ was considered, this ratio remained virtually unchanged $(1: 4.39)$.

Figure 1, which depicts the log ratio of right handed to left handed subjects, shows that the

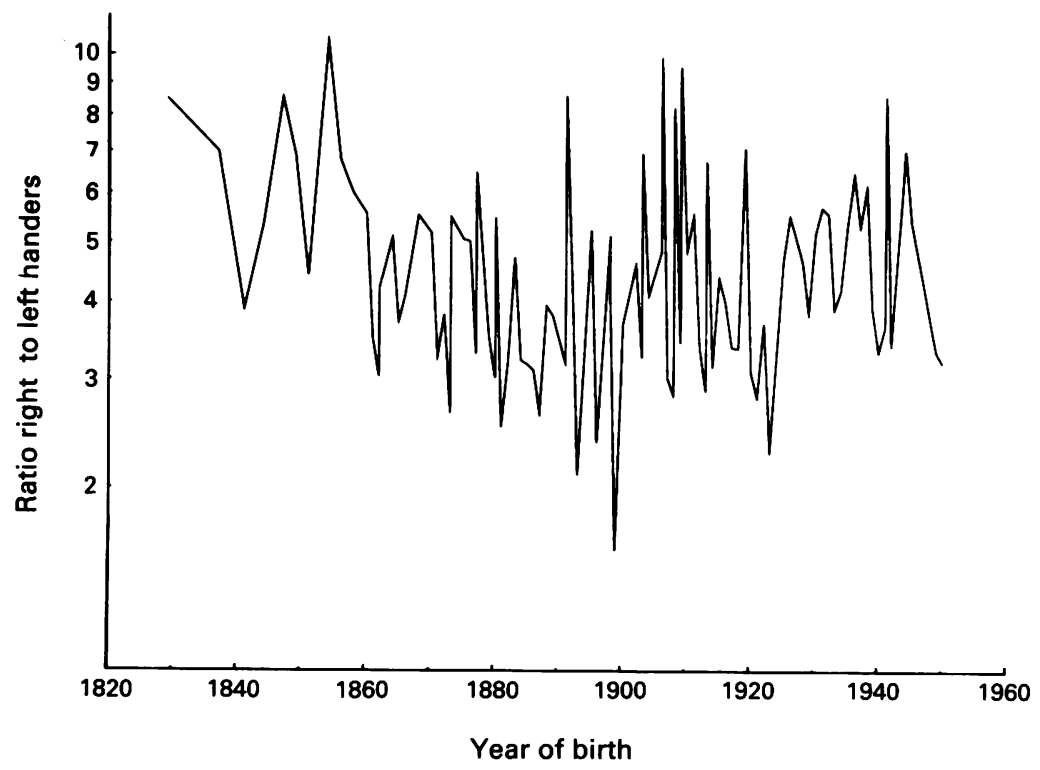

Figure 1. Relative frequency of left handed players (as defined by bowling hand) across time period of sample. Starting at the earliest birth year the left handed players were put in consecutive bins of 10 and compared with the number of right handers born in the same period. The ratio of right handers to left handers is plotted on a logarithmic scale.

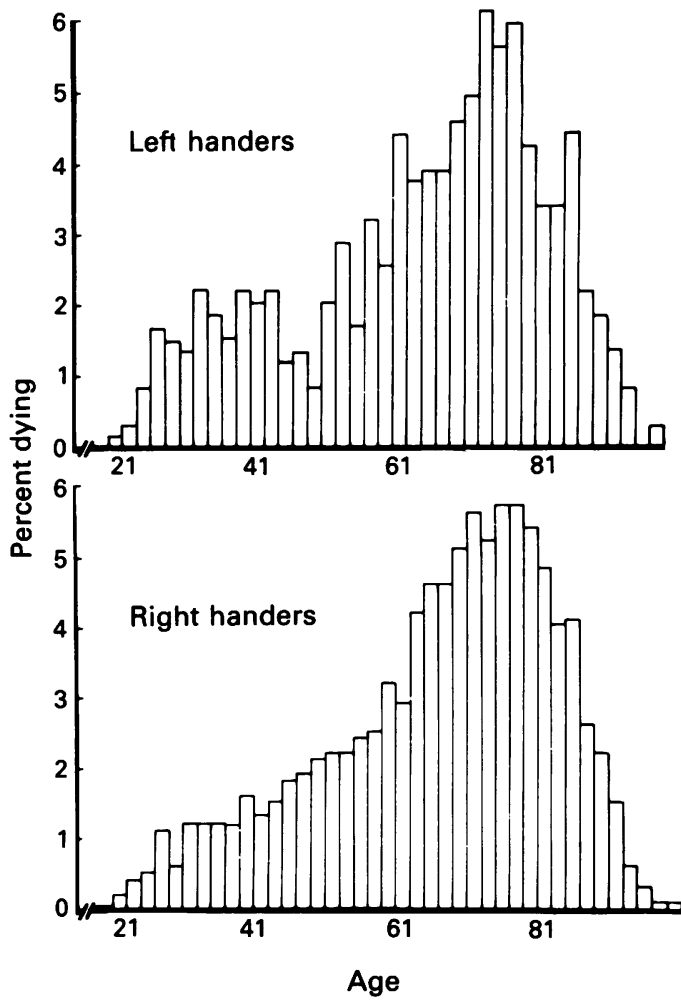

Figure 2 Longevity of right (lower) and left (upper) handed cricketers. Each column represents the percentage of players of a given handedness dying at a particular age (each column represents two ycars). The data concern all of those players who died before 1984 whose bowling hand was specified.

population of left handed subjects remained stable across the time period of the investigation. This stability was reflected in the flatness of a line fitted to this data by linear regression (log (ratio) $=4 \cdot 06-$ 0.00136 year). The lack of any clear overall change in this ratio $(F(1,98)=1 \cdot 27)$ makes it appropriate to use the entire population of decreased cricketers to compare life expectancy.

The mean (SD) lifespans of the two groups of deceased cricketers were: left, $63.52(17 \cdot 51)$ and right $65 \cdot 62(16 \cdot 28)$. This difference of 25 months was highly significant $(t(3163)=2 \cdot 77, \mathrm{p}=0 \cdot 006$, two tailed).

An examination of the causes of death showed a clear difference between the two groups. Of 147 players specified as dying of unnatural causes (including transport accidents, drownings, players killed in action, but excluding suicide), 42 were left handed and 105 were right handed. This proportion of left handers who had died of unnatural causes was much higher than that in the overall population of deceased players $\left(\chi^{2}=10 \cdot 28, p=0 \cdot 0013\right)$. This higher likelihood of premature death, which was found both in those specified as killed in action (28 left:68 right) and those killed in other ways (14 left:37 right), is reflected in the lifespans of the two groups (fig 2).

The lifespans of the two groups were then compared after removing the 147 players who had been specified as dying of unnatural causes. This more than halved the mean lifespan difference to 11.04 months, and there was now no statistical difference between the left handers and right handers $(t(3016)=1 \cdot 27, \mathrm{p}=0 \cdot 20)$. This difference was further reduced to $10 \cdot 1$ months by excluding an additional 22 players in a 'roll of honour' of 
First World War deaths ${ }^{20} 21$ or whose location and date of death (for example Normandy, 1944) placed them in a battle area. Further evidence that, barring accidents, the two groups reached equivalent ages comes from the ratio of left handers to right handers reaching 90 years or more (15:71) which closely matched that in the overall population (1:4.39). This comparison was selected because in a study of baseball players ${ }^{5}$ it was suggested that significantly fewer left handers live to such extreme ages.

To compare the survival rates of left handers and right handers directly, we calculated the number of deceased players born between 1880 and 1950. These were then compared with the number of players still alive in 1984 and born during the same period. The year 1950 was selected as two subjects only from the entire sample of deceased players were born after that year. The percentage of surviving right handers $(66.2 \%$, total $n=2845)$ differed from that of the left handers $(59 \cdot 5 \%$, total $n=725)$. This was highly significant $\left(\chi^{2} 11.50, p<0.001\right)$. The exclusion of those players known to have died accidentally or in wartime reduced, but did not eliminate, this difference (right $=68 \cdot 0 \%$, left $=62 \cdot 5 \%, \chi^{2}=7 \cdot 72$, $\mathrm{p}<0.01)$.

A final set of analyses considered only the subset of players who used the same hand for both bowling and batting. The mean age of the left handers was $62 \cdot 26$ years $(n=264)$ while that of the right handers was 65.80 years $(n=2209)$. Once again, right handedness was associated with a significantly longer life span $(t(2471)=3.35$, $\mathrm{p}=0.001)$. This difference in longevity was reduced by approximately 14 months when all of the subjects who were known to have died in accidents or in warfare were removed from the sample (left=64.90: right=67·17). Nevertheless, this difference remained significant $(t$ $(2352)=2 \cdot 24, p=0 \cdot 025)$.

\section{Discussion}

This study compared the lifespans of 3165 deceased cricketers in relation to their bowling hand. Cricketers were chosen because the nature of the sport allows us to identify those who use their right hand or left hand, and because it is a sport that has been very well documented over many decades. As a consequence cricket provides an almost unique source of information to examine life expectancy and handedness in a very large cohort of subjects.

Clearly, the validity of this study must depend on whether bowling hand is a good indicator of handedness. Evidence for this comes from the fact that the item 'throwing hand' is widely used in handedness questionnaires and correlates well with the factor 'handedness'.17 It is also known that the specific action of bowling a cricket ball is strongly associated with other measures of handedness. ${ }^{16}$ Furthermore, as bowling in first class cricket is a highly skilled action and left handers have long been valued, it is most unlikely that one would become a proficient bowler using the non-preferred hand. Finally, it should be noted that the use of a stricter criterion for handedness (that is, considering only those who used the same hand for both bowling and batting) produced a very similar set of results.
The present study found that for a large sample of adult men, those who used their right hand lived on average about two years longer than their left handed counterparts. There was also clear evidence that an important part of this difference was the result of an increased vulnerability to both accidental death and death during warfare. Such a result could have been produced artifactually if the proportion of left handers had been particularly high for those players born before the two world wars. It is, however, possible to discount this suggestion. Firstly, the ratio of right handers to left handers remained quite stable across the sample. Secondly, it was possible to take the proportion of left handers among all of the players (dead or alive) born between 1880 and 1925 (1:4.28) and apply this to the overall sample of 3165 deceased players. The frequency of left handers and right handers in the resultant, hypothetical population (599 left: 2566 right) was then compared with that in the set of 147 players specified as dying in warfare or in accidents. This slightly more conservative analysis still indicated that more left handers died of unnatural causes than would have been expected by chance $\left(\chi^{2}=9.35, p<0.005\right)$.

Removal from the sample of the known cases of unnatural death decreased noticeably the lifespan difference between the left handers and right handers. The fact that a significant difference still remained in those analyses looking at survival rates and at those players who used the same hand for bowling and batting, suggests that some other factor may produce a right handed advantage. It is also possible that the encyclopaedia did not mention all the cases of unnatural death, and had it done so the difference might have become non-significant.

In considering the present findings, it should perhaps be recalled that the subjects were not representative of any general population. Limitations include the lack of women, there being no comparable data source for female cricketers, and the fact that the subjects were athletic men who had already reached the age of at least 18 years. As a consequence, there is no guarantee that the present findings can be applied to all men. Nevertheless, it is difficult to envisage why accomplished left handed cricketers should be particulary different in regard to mortality rates from the $10 \%$ of the adult male population who throw left handed. ${ }^{17}$ It should be added that the much higher proportion of left handers among the cricketers than among the general population is neither new nor unexpected. ${ }^{16}$ There are well known strategic and tactical advantages enjoyed by the less frequent left handed player, and these are probably sufficient to account for the relative excess of such cricketers. ${ }^{16}$

The most likely explanation for the increase in accidental death among the left handed men concerns their need to cope in a world full of right handed tools, machines, and instruments. In the case of warfare this could extend to the problems of a left handed person being trained to use the right hand. This proposal is consistent with evidence that left handed men may be at an increased risk of accident related injury or death ${ }^{6}{ }^{7}$ It should be noted however, that part of this evidence came from a student survey ${ }^{6}$ and it is not known whether it applies to more representative populations. 
While it is possible that left handed men are more heroic or more prone to disregard their own safety, there is no evidence to support such an unlikely claim.

The present findings may well help to resolve the controversy concerning a previous archival survey of handedness and longevity. ${ }^{5}$ In that study of US baseball players, based on a much smaller sample of 1472 right handers and 236 left handers, it was reported that overall the left handers died eight months younger than the right handers. ${ }^{5}$ Subsequent re-analysis of the data indicated, however, that this did not represent a clear statistical difference between the groups. ${ }^{89}$ This finding is not, in fact, inconsistent with the present results if it assumed that a smaller proportion of the baseball players died in warfare. In view of the large numbers of cricketers who were killed (3.7\% of the total sample), especially during the two world wars, this seems to be quite plausible. Thus, it seems that, barring accidental deaths, the lifespans of left and right handed men are similar. ${ }^{22}$ It now remains to look at other sources of evidence to test the notion that left handers are more susceptible to death during warfare or from accidents, and to determine whether there are other factors contributing to this apparent decrease in life span for left handed men.

The authors thank M Ferguson, C Wood, S Baker, and $\mathrm{G}$ Dooley for assistance.

1 Porac C, Coren S, Duncan P. Life-span age trends in laterality. $f$ Gerontol 1980; 35: 715-21.
2 Fleminger JJ, Dalton R, Standage KE. Age as factor in the handedness of adults. Neuropsychologia 1977; 15: 471-3.

3 Beukelar LJ, Kroonenberg PM. Changes over time in the relationship between hand preference and writing hand among left handers. Neuropsychologia 1986; 24: 301-3.

4 Coren S, Halpern DF. Left-handedness: a marker for decreased survival fitness. Psyuchol Bull 1991; 109: 90-106.

5 Halpern DF, Coren S. Do right-handers live longer? Natur 1988; 333: 213.

6 Coren S. Left-handedness and accident-related injury risk. Am f Public Health 1989; 79: 1-2.

7 Halpern DF, Coren S. Handedness and life span $N^{\circ}$ Engl $\mathcal{F}$ Med 1991; 324: 998.

8 Wood EK 324. 98 . Nature 1988; 335: 212.

9 Anderson MG. Lateral preference and longevity. Nature Anderson MG.

10 Geschwind N, Behan P. Left-handedness: associations with immune disease, migraine, and developmental learning disorders. Proc Natl Acad Sci USA 1982; 79: 5097-100.

11 Searleman A, Fugagli A. Suspected autoimmune disorders and left-handedness: Evidence from individuals with diabetes, Crohn's disease and ulcerative colitis. Neuropsychologia 1987; 25: 367-74

12 Smith J. Left-handedness: its association with allergic disease. Neuropsychologia 1987; 25: 665-74.

13 Bishop DVM. Is there a link between handedness and hypersensitivity? Cortex 1986; 22: 289-96.

14 Bryden MP, McManus IC, Steenhuis RE. Handedness is not related to self-reported disease incidence. Cortex 1991 27: $605-11$.

15 Stanton WR, Feehan M, Silva PA, Sears MR. Handedness and allergic disorders in a New Zealand cohort. Cortex 1991 ; 27: 131-6.

16 Wood CJ, Aggleton JP. Handedness in 'fast ball' sports: do left-handers have an innate advantage? $B r f$ Pswchol 1989 ; 80: $227-40$.

17 Bryden MP. Measuring handedness with questionnaires. Neuropsychologia 1977; 15: 617-24.

18 Bailey P, Thorn P, Wynne-Thomas P. Who's who of cricketers. Feltham: Newnes Books, 1984

19 Keppel G. Design and analysis: a researcher's handbook. Englewood Cliffs, New Jersey: Prentice-Hall, 1973

20 Thorn P. The roll of honour. Cricket Statistician 1982; 37: 30-2.

21 Thorn P. The roll of honour. Cricket Statistician 1984; 45 27-9.

22 Kuhlemeier KV. Longevity and left-handedness. Am f Public Health 1991; 81: 513 . 